\title{
MIMR SLEEP DISORDER AND SLEEP QUALITY AMONG HOSPITALIZED ADULT PATIENTS WITH CHRONIC DISEASES IN HOSPITAL UNIVERSITI SAINS MALAYSIA
}

\author{
Soh Shi Ting*, Dariah Mohd Yusoff \\ School of Health Sciences, Universiti Sains Malaysia, Malaysia \\ *Corresponding Author Email: shiting_94@live.com.my
}

\begin{abstract}
Sleep has restorative function that is important in the maintenance of life. Yet poor sleep quality has been reported by people with chronic diseases including cardiovascular diseases, hypertension, Type II diabetes mellitus and chronic kidney diseases. A cross-sectional study to determine their sleep disorder and sleep quality was carried out among hospitalized adult patients with chronic diseases in Hospital Universiti Sains Malaysia. A total of 117 respondents, male (61.5\%) and female (38.5\%), aged between 18 and 90 years old who fulfilled the inclusion criteria were selected through systematic sampling. Data collection was statistically analyzed using the SPSS software version 22.0. Oneway ANOVA, Independent $t$-test and Pearson Chi-square were used for data analysis. The results showed that the prevalence of sleep disorder was $59.0 \%$ and majority of them had poor sleep quality (74.4\%). However, the results showed that there is no significant association between socio-demographic characteristics of the respondents and sleep quality. In Each chronic disease it was found that there is no significant association with it to the patients' sleep quality during the period of hospitalization. This might be due to the quality of sleeping of the individuals. Most probably it would not be affected by having only one single chronic disease. On the other hand, a significant association was found between sleep disorder and sleep quality as sleep disorder would lead to shallow sleep and awakening from sleeping. In conclusion, the poor sleep quality level of hospitalized patients with chronic diseases might be occurred due to other causes such as environmental factors. .
\end{abstract}

Keywords: Sleep Disorder, Sleep Quality, Chronic Diseases

\section{INTRODUCTION}

There is no clear definition for sleep quality. Yet National Sleep Foundation (2017) defines sleep quality as one's satisfaction of the sleep experience, integrating aspects of sleep initiation, sleep maintenance, sleep quantity, and refreshment upon awakening. According to Smith, Robinson \& Segal (2017), though sleep requirement varies from person to person, most people require at least seven hours of sleep per night to function at their best. However, the requirement of sleep may change as a normal part of aging, medical problems, medications, and treatments (American Sleep Association, 2017). According to Kripke et al., (2011), the estimated mortality for sleeping less than five hours was almost four times greater than those who sleep more than five hours.

Sleep has restorative function that is important in the maintenance of life (Barbosa et al., 2016). There are five stages of sleep and rapid eye movement (REM) sleep (Kishi et al., 2011). Stage 1 refers to light sleep and people can be awakened easily. In Stage 2, there will be absent of eye movements and brain waves with occasional bursts of rapid waves where sleep spindles is formed. Both stage 3 and stage 4 are called deep sleep where the person is nearly completely disengaged from the environment (Kishi et al., 2011; National Sleep Foundation, 2017). It is difficult to wake someone during these stages (National Sleep Foundation, 2017). When switching to REM sleep, people will have rapid breathing, elevated heart rate and temporarily paralyzed limb muscles. Besides, dream gets developed in this stage (National Sleep Foundation, 2017).

Sleep disorder is a medical term used to represent the disorder of sleeping. American Psychiatric Association (2017) defined sleep disorders as the problems which will alter the quality, timing, and amount of sleep that will cause problem of functing and distress during daytime. According to Ünsal and Demir (2012), there are more than 70 sleep disorders. Sleep disorders are typically viewed as symptomatic problems rather than 
a diagnosable disorder (Ünsal \& Demir, 2012). The common sleep disorders experienced by hospitalized patients are circadian rhythm disruption, insomnia, and sleep apnea (Holland et al., 2010).

Poor sleep quality has significant impact on health particularly those with co-morbid conditions (Gangwisch et al., 2008; Barbosa et al., 2016). Sleep acts as a source of replenishment which will refresh the mind and body (Anderson, 2010). Energy, efficiency, and overall health will boost up with adequate sleep (Smith, Robinson \& Segal, 2017). Sleep quality is associated to the quality of life, daily functioning, and well-being (Smith, Robinson \& Segal, 2017). Sleep quality is crucial as it is related to mental health, emotional health, and physical health (Smaldone, Honig \& Byrne, 2007; Smith, Robinson \& Segal, 2017). Other than that, Gangwisch et al. (2008) also claimed that having too much or too less of sleep will affect one's health status.

A study by Palacios Ceña et al. (2017) reported that poor sleep quality will indirectly cause depression, emotional burden, and pain interference on headache frequency. Moreover, poor sleep quality leads to excessive daytime sleepiness besides decreasing health-related quality of life (Liam et al., 2007; Punjabi, 2008). Obviously, it has serious consequences which linked to fatigue, slowed recovery from illness, immune dysfunction, changes in mental status, impaired brain activity and diminished quality of life (Hacker et al., 2015; American Sleep Association, 2017). Other than that, observational and experimental studies also suggested that poor sleep quality may contribute to the development of chronic diseases (Punjabi, 2008; Krueger \& Friedman, 2009; Zailinawati, Mazza \& Cheong, 2012).

As reported by other studies, old age, male, high Body Mass Index (BMI), snoring, smoking, metabolic syndrome and high blood pressure are the risk factors of poor sleep quality (Wang et al., 2014; Hein et al., 2017). Wali, Abalkhail \& Krayem (2017) indicated that elderly people had 2 to 4 times higher tendency of having poor sleep quality while poor sleep quality among male might happen due to the difference of hormonal effects among gender. Other than that, hospitalization also elevate the risk of poor sleep quality (Sharma et al., 2016). From a Turkish study it is known that among the hospitalized patients poor sleep quality during hospitalization might happen due to exogenous and endogenous factors which are environmental and biological factors respectively. (Ünsal \& Demir, 2012).

Chronic diseases are also known as non-communicable diseases (World Health Organization, 2017). The World Health Organization (2017) has defined chronic diseases as the diseases with long duration, slow progression, and non-contagious. It is acknowledged that cardiovascular disease (CVDs), systemic hypertension, and abnormal glucose metabolism or Type II Diabetes Mellitus (Type II DM) and chronic kidney disease (CKD) are the common chronic diseases reported by the patients with poor sleep quality (Gangwisch et al., 2008; Krueger \& Friedman, 2009). However, for this study the researcher focuses mainly on four main chronic diseases, which are CDVs, Hypertension, Diabetes Type II and Chronic kidney failure (CKD) among hospitalized patients.

In Malaysia, it was reported that the prevalence of chronic diseases has risen with the increase of age (Institute for Public Health, 2015). The prevalence of chronic diseases in Malaysia is reported from 6.7\% among the adolescence and it is getting reached to the peak of $75.4 \%$ among elderly (Institute for Public Health, 2015). The total number of hospitalized patients with chronic diseases in medical wards, Hospital USM has apparently increased from 170 in 2012 to 547 in 2016 (Record Unit, Hospital USM).

\section{Aim}

The general objective of this study was to assess sleep disorder and sleep quality among hospitalized adult patients with chronic diseases in the Hospital of Universiti Sains Malaysia (Hospital USM).

\section{RESEARCH METHODOLOGY}

\section{Study design and setting}

A cross-sectional study design was employed in this study. This study was conducted among the hospitalized adult patients who have chronic diseases in Hospital USM.

\section{Population and sampling method}

Single proportion formula and double proportion formula were used in calculating the sample size of this study. The respondents in this study were selected 
using systematic sampling method. They were among hospitalized male and female patients who had fulfilled the inclusion criteria (aged above 18 years, had been diagnosed with at least one chronic disease for more than 3 months, admitted at medical wards of Hospital USM for at least 3 days, being conscious, able to understand and speak in Malay or English and agreed to participate in this study).

\section{Ethical approval}

Ethical approval to conduct this study was obtained from the Research Ethical Committees (Human), Universiti Sains Malaysia. Permission to conduct the study was obtained from the Director of Hospital USM. Written consent was obtained from the participants after they fully understood the process of the study.

\section{Questionnaire design}

The instrument used in this study was a selfadministered questionnaire adapted from Buysse (1989) with three sections: Part A, B and C.

Part A was used to gather socio-demographic data.

Part B was used to assess the prevalence of sleep disorder among patients with chronic diseases during the period of hospitalization.

Part C consisted of nine questions. Sleep quality of each respondent was determined by measuring seven aspects: subjective sleep quality, sleep latency, sleep duration, habitual sleep efficiency, and sleep disturbance, use of sleep medication, and daytime dysfunction over the past three days staying in hospital (Lai \& Say, 2013). Each component in Part C is scored from " 0 " to "3" points. Score "0" indicated better sleep quality while score of " 3 " indicated worse sleep quality. However, global scores of the Pittsburgh Sleep Quality Index (PSQI) questionnaire were obtained by summing all the scores of the seven components. When PSQI scored more than five points by a particular patient, he or she is classified as poor sleeper (Ünsal \& Demir, 2012; Gezer et al., 2017).

\section{Validity and Reliability}

The original version of the questionnaire used in this study was in English and the translation process into
Malay language was done by the researcher and checked by a bilingual expert. Other than that, four experts did the content validation. A pilot study was conducted on 10 adults prior to the real study to ensure the questionnaire is reliable and understandable by the respondents.

\section{Data Analysis}

Data of this study was analyzed by using Statistical Package for Social Science (SPSS) software version 22.0. Based on the objectives, descriptive and inferential analyses were performed accordingly. Frequency (f) and percentage (\%) were used to identify the prevalence of sleep disorders and determine the level of sleep quality among hospitalized adult patients with chronic diseases in Hospital USM. One-way ANOVA and Independent $t$-test were used to determine the mean difference between socio-demographic characteristics and sleep quality among hospitalized adult patients with chronic diseases in Hospital USM. Pearson's Chi-square was used to determine the association between between chronic diseases and patients' sleep quality during hospitalization period.

\section{RESULTS}

Altogether there were 117 respondents participating in this study with $100.0 \%$ response rate.

Table1 shows the socio-demographic characteristics of the respondents. The ages of respondents were ranged from 18 to 90 with mean age of 54.85 years $(S D=15.02)$. In terms of age, $54.7 \%$ of the respondents were above 55 years old. Most of the respondents were male $(n=72,72.0 \%)$ and were Malay $(n=111,94.9 \%)$. In terms of educational level, most of the respondents had secondary education level $(n=62,53.0 \%)$. Besides, most of the respondents were married $(n=98,83.8 \%)$ and $103(88.0 \%)$ had children with the median number of children $4(I Q R=4)$. In terms of hospitalization, many of the respondents had previous hospitalized experience $(n=93,79.5 \%)$. In terms of chronic disease, most of the respondents had hypertension $(n=82$, $70.1 \%)$. 
Table 1: Socio-demographic characteristics of the respondents

\begin{tabular}{|c|c|c|c|}
\hline Socio-demographic & Frequency $(n)$ & Percentage (\%) & Mean (SD) \\
\hline Age & & & $54.85 \pm 15.02$ \\
\hline 18-35 (Young adult) & 14 & 12.0 & \\
\hline 36-55 (Middle adult) & 39 & 33.3 & \\
\hline 56-90 (Old adult) & 64 & 54.7 & \\
\hline \multicolumn{4}{|l|}{ Gender } \\
\hline Male & 72 & 61.5 & \\
\hline Female & 45 & 38.5 & \\
\hline \multicolumn{4}{|l|}{ Ethnicity } \\
\hline Malay & 111 & 94.9 & \\
\hline Chinese & 5 & 4.3 & \\
\hline India & 1 & 0.9 & \\
\hline \multicolumn{4}{|l|}{ Educational level } \\
\hline Primary school & 26 & 22.2 & \\
\hline Secondary school & 62 & 53.0 & \\
\hline Diploma/ STPM/ Matriculation & 9 & 7.7 & \\
\hline Degree & 10 & 8.5 & \\
\hline Master & 2 & 1.7 & \\
\hline $\mathrm{PhD}$ & 1 & 0.9 & \\
\hline Others & 7 & 6.0 & \\
\hline \multicolumn{4}{|l|}{ Marital status } \\
\hline Married & 98 & 83.8 & \\
\hline Single & 8 & 6.8 & \\
\hline Widow/ Widower & 10 & 8.5 & \\
\hline Divorced & 1 & 0.9 & \\
\hline \multicolumn{4}{|l|}{ Hospitalization experience } \\
\hline Yes & 93 & 79.5 & \\
\hline No & 24 & 20.5 & \\
\hline \multicolumn{4}{|l|}{ Current illness } \\
\hline CVDs & 63 & 53.8 & \\
\hline HPT & 82 & 70.1 & \\
\hline Type II DM & 59 & 50.4 & \\
\hline CKD & 49 & 41.9 & \\
\hline
\end{tabular}

Table 2 shows the factors that affected sleep quality of the respondents. Majority of the respondents complained of cannot sleep within 30 minutes ( $n=68,58.1 \%$ ), wake up in the midnight ( $n=99,84.6 \%$ ), wake up to go to the toilet $(n=64,54.7 \%)$ and cough or snore $(n=59,50.4 \%)$.
Some of the respondents also complained of mosquitoes $(n=3,2.6 \%)$, noise $(n=3,2.6 \%)$, procedure disturbance $(n=9,7.7 \%)$, lighting $(n=25,21.4 \%)$, psychological disturbance $(n=3,2.6 \%)$ and broken bed $(n=1,0.9 \%)$ that got disturbance their sleep during hospitalization. 
Table 2: Factors that affecting sleep quality of the respondents

\begin{tabular}{|l|c|c|}
\hline Factors & Frequency $(\boldsymbol{n})$ & Percentage (\%) \\
\hline Cannot sleep within 30 minutes & 68 & 58.1 \\
\hline Wake up in the midnight & 99 & 84.6 \\
\hline Wake up to go to the toilet & 64 & 54.7 \\
\hline Difficulty in breathing & 33 & 28.2 \\
\hline Cough or snore & 59 & 50.4 \\
\hline Too cold & 33 & 28.2 \\
\hline Too hot & 53 & 45.3 \\
\hline Having nightmare & 14 & 12.0 \\
\hline Pain & 52 & 44.4 \\
\hline Others & \multicolumn{2}{|c|}{} \\
\hline Mosquitoes & 3 & 2.6 \\
\hline Noise & 3 & 2.6 \\
\hline Procedure disturbance & 9 & 7.7 \\
\hline Lighting & 25 & 21.4 \\
\hline Psychological disturbance & 3 & 2.6 \\
\hline Broken bed & 1 & 0.9 \\
\hline
\end{tabular}

Figure 1 shows the prevalence of sleep disorder among the respondents of this study. More than half of the respondents self-claimed that they had sleep disorder $(n=69,59.0 \%)$.

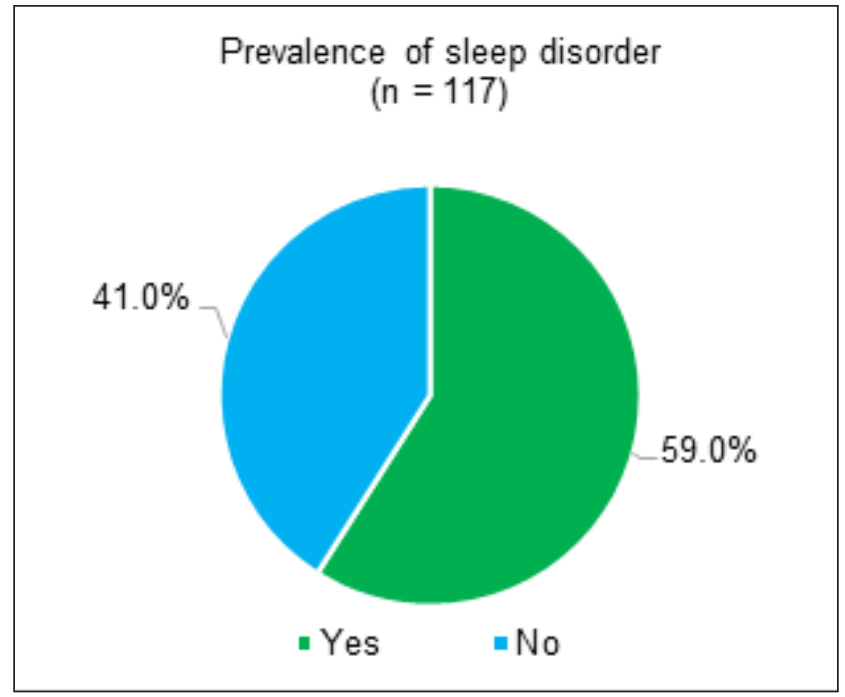

Figure 1: Prevalence of sleep disorderl

Figure 2 shows the respondents' sleep quality level. Majority of the respondents had poor sleep quality based on the PSQI $(n=87,74.4 \%)$. Respondents with PSQI higher than 5 is considered as poor sleep quality.

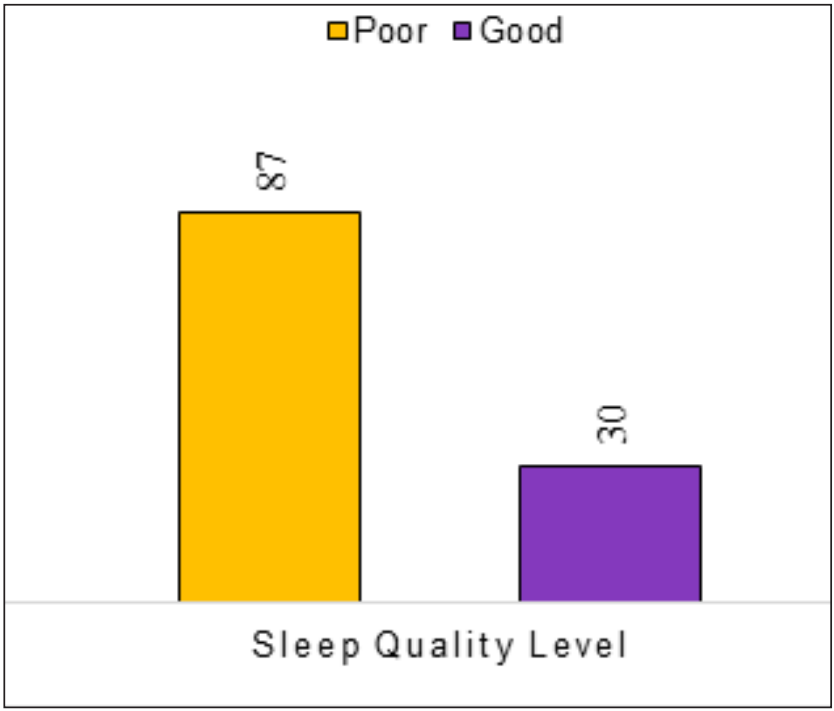

Figure 2: Sleep quality level

Association between socio-demographic characteristics and sleep quality was tested to fulfil the third research objective using independent t-test and One-way ANOVA. Table 3 shows that there is no significant mean difference between age, ethnicity, gender, educational status, and marital status and sleep quality among hospitalized patients with chronic diseases in Hospital USM. 
Table 3: Mean difference between age, ethnicity, educational status, and marital status and sleep quality

\begin{tabular}{|l|c|c|c|}
\hline Variables & Mean (SD) & F statistic (df) & p value \\
\hline Age & & $0.07(2)$ & 0.93 \\
$18-35$ (Young adult) & $7.50(2.74)$ & & \\
$36-55$ (Middle adult) & $7.84(2.85)$ & & \\
56-90 (Old adult) & $7.74(3.01)$ & & 0.53 \\
\hline Ethnicity & & \\
Malay & $7.79(2.87)$ & & \\
Chinese & $6.40(4.04)$ & & \\
Indian & $9.00(0.00)$ & & \\
& & \\
\hline Educational level & & \\
Primary school & $8.08(2.61)$ & & \\
SPM & $7.53(3.02)$ & & \\
Diploma/ STPM/ Matriculation & $7.89(3.14)$ & & \\
Degree & $7.60(2.88)$ & & \\
Master & $9.00(1.41)$ & & \\
PhD & $3.00(0.00)$ & & \\
Others & $8.71(3.15)$ & & \\
\hline Marital status & $7.82(3.00)$ & & \\
Married & $7.63(2.62)$ & & \\
Single & $6.80(2.04)$ & & \\
Widow/ widower & $11.00(0.00)$ & & \\
Divorced & & \\
\hline
\end{tabular}

Note: Tested using One-way ANOVA.

Besides, Table 4 also shows no significant mean difference between gender and experience of hospitalization and sleep quality among hospitalized patients with chronic diseases in Hospital USM.

Table 4: Mean difference between gender and experience of hospitalization and sleep quality

\begin{tabular}{|c|c|c|c|c|c|}
\hline \multicolumn{2}{|l|}{ Variable } & Sleep quality & $\begin{array}{l}\text { Mean different } \\
(95 \% C I)\end{array}$ & $\begin{array}{cc}\text { statistic } \\
\text { (df) }\end{array}$ & $\begin{array}{l}p \\
\text { value }\end{array}$ \\
\hline \multirow{2}{*}{$\begin{array}{l}\text { Gender, Mean } \\
(S D)\end{array}$} & Male & $7.64(2.81)$ & \multirow{2}{*}{$\begin{array}{l}-0.27 \\
(-1.37,-1.40)\end{array}$} & \multirow{2}{*}{$\begin{array}{r}-0.49 \\
(115)\end{array}$} & \multirow[t]{2}{*}{0.62} \\
\hline & Female & $7.91(3.09)$ & & & \\
\hline \multirow{2}{*}{$\begin{array}{l}\text { Experience of } \\
\text { hospitalization, } \\
\text { Mean }(S D)\end{array}$} & Yes & $7.78(3.01)$ & \multirow{2}{*}{$\begin{array}{l}0.20 \\
(-1.12,-1.02)\end{array}$} & \multirow{2}{*}{$\begin{array}{l}0.30 \\
(115)\end{array}$} & \multirow[t]{2}{*}{0.76} \\
\hline & No & $7.58(2.54)$ & & & \\
\hline
\end{tabular}

Note: Tested using Independent t-test.

Table 5 showed that there was no significant association between all four chronic diseases and patients' sleep quality during hospitalization period. 
Table 5: Association between each chronic diseases and patients' sleep quality during hospitalization period

\begin{tabular}{|c|c|c|c|c|c|}
\hline \multicolumn{2}{|l|}{ Variable } & \multicolumn{2}{|c|}{ Sleep quality } & \multirow[t]{2}{*}{$X^{2}(\mathrm{df})$} & \multirow[t]{2}{*}{$p$ value } \\
\hline & & \multirow{2}{*}{$\begin{array}{l}\text { Good } \\
18(15.4)\end{array}$} & \multirow{2}{*}{$\begin{array}{l}\text { Poor } \\
45(38.5)\end{array}$} & & \\
\hline Presence of CVDs, n (\%) & Yes & & & \multirow[b]{2}{*}{$0.62(1)$} & \multirow[b]{2}{*}{0.43} \\
\hline & No & $12(10.3)$ & $42(35.9)$ & & \\
\hline \multirow[t]{2}{*}{ Presence of HPT, n (\%) } & Yes & $19(16.2)$ & $63(53.8)$ & \multirow[b]{2}{*}{$0.88(1)$} & \multirow[b]{2}{*}{0.35} \\
\hline & No & $11(9.4)$ & $24(20.5)$ & & \\
\hline \multirow[t]{2}{*}{ Presence of Type II DM, n(\%) } & Yes & $15(12.8)$ & $44(37.6)$ & \multirow[b]{2}{*}{$0.03(1)$} & \multirow[b]{2}{*}{0.96} \\
\hline & No & $15(12.8)$ & $43(36.8)$ & & \\
\hline \multirow[t]{2}{*}{ Presence of CKD, n (\%) } & Yes & $11(9.4)$ & $38(32.5)$ & \multirow[b]{2}{*}{$0.45(1)$} & \multirow[b]{2}{*}{0.50} \\
\hline & No & $19(16.2)$ & $49(41.9)$ & & \\
\hline
\end{tabular}

Note: Tested using Pearson's Chi-square.

Table 6 showed that there was a significant association between sleep disorder and patient's sleep quality during hospitalization in Hospital USM.

Table 6: Association between sleep disorder and patient's sleep quality during hospitalization period

\begin{tabular}{|l|l|c|c|c|c|}
\hline \multicolumn{2}{|l|}{ Variable } & \multicolumn{2}{|c|}{ Sleep quality } & \multirow{2}{*}{$\boldsymbol{X}^{2}(\mathbf{d f})$} & \multirow{2}{*}{$\boldsymbol{p}$ value } \\
\cline { 3 - 4 } \multicolumn{2}{|l|}{ Sleep disorder } & Good & Poor & & $<0.00 \%^{*}$ \\
\cline { 2 - 4 } & No & $4(3.4 \%)$ & $65(55.6 \%)$ & \multirow{2}{*}{$34.74(1)$} & \\
\hline
\end{tabular}

Note: Tested using Pearson's Chi-square.

*Statistically significant

\section{DISCUSSION}

\section{Factors that Affect Sleep Quality:}

\section{Cannot sleep within 30 minutes}

This study showed that majority of the respondents cannot sleep within 30 minutes or have difficulty in falling asleep $(n=68,58.1 \%)$ and this is similar with other study whereby majority of the respondents have difficulty in falling asleep (Haile, Alemu \& Habtewold, 2017). Besides, Isaia et al. (2011) suggested that age, chronic diseases and especially hospitalization are usually associated with difficulty in falling asleep. Ünsal and Demir (2012) also found that hospitalized patients cannot sleep within 30 minutes might due to worry, fear, and pain of their diseases.

\section{Wake up in the midnight}

This study showed that $84.6 \%$ of the respondents $(n=99)$ needed to wake up in the midnight or experienced frequent night awakening. Similar result was indicated by Zailinawati, Mazza \& Cheong (2012). Sleep disorders, underlying conditions and environment would cause frequent night awakening (Chan, 2016). Sleep disorder throughout the night would disturb sleep and thus, trigger awakening from sleep (Chan, 2016). Besides, the external disturbance especially light, temperature, and noise were the main factors that will disturb a restful sleep (Clares et al., 2012; Healthy Sleep, 2007).

\section{Wake up to go to the toilet}

This study showed that there were $54.7 \%$ respondents ( $n=64)$ who experienced waking up to go to the toilet or nocturia at least one day during hospitalization. Similar result was indicated in other studies in which nocturia were affecting most of the hospitalized patients (Prince, Pedler \& Rashid, 2012). Voiding of two or more times 
per night might be more clinically relevant and better related to poor sleep quality (Tikkinen et al., 2010). Nocturia can be caused by a variety of factors such as the production of arginine vasopressin (AVP) hormone, excessive production of atrial natriuretic peptide and diuretic medications which are common in patients with chronic disease (Cornu et al., 2012). Moreover, a research found that nocturia may take place due to lesions of the central nervous system (CNS) that affect the hypothalamic-pituitary axis, but nocturia can be happened among elderly without specific CNS pathology (Prince, Pedler \& Rashid, 2012).

\section{Cough or snore}

This study indicated that there were $50.4 \%$ of the respondents $(n=59)$ who complained of cough or snore during hospitalization. Previous study also indicated similar finding in which most of the hospitalized patients were coughed or snored (Park et al., 2017). In addition, research found that snoring can be a sign of obstructive sleep apnea and it has been linked to chronic diseases such as obesity and heart diseases (Park et al., 2017). Coughing and snoring can disturb the sleep quality of the patient and the bed-partner of the patient as it may lead to fragmented sleep and nonrefreshed sleep (National Sleep Foundation, 2017).

\section{Prevalence of sleep disorder}

The prevalence of sleep disorder was $59.0 \%$, based on self-rated sleep disorder. This is similar to the findings of previous studies whereby majority of the participants had sleep disorder (Mbatchou Ngahane et al., 2015; Ismail et al., 2017). Study showed that the prevalence of sleep disorder increases as a person ages (Kim et al., 2010). The high prevalence of sleep disorder may due to majority of the participants in this study were older adults which aged more than 55 years old. ( $n=64,54.7 \%)$. Besides, other study also showed that people with chronic diseases tends to have higher prevalence of sleep disorder than general population due to the disease process (Mbatchou Ngahane et al., 2015).

\section{Sleep quality level}

In terms of sleep quality, $74.4 \%$ of the respondents had poor sleep quality during hospitalization in Hospital
USM. Similar result was indicated in other studies in which sleep quality of hospitalized patients is often impaired (Azri et al., 2016; Auckley, Benca \& Eichler, 2018).

The presence of sleep disorder will affect sleep quality directly (Auckley, Benca \& Eichler, 2018). Study explained that hospitalized patients tend to have fragmented sleep, absence of deep sleep, and circadian rhythm disturbance (Auckley, Benca \& Eichler, 2018). Sleep quality could decrease with the increasing of age (Costa \& Ceolim, 2013). The high prevalence of poor sleep quality may happen due to the fact that most of the respondents were older adults (54.7\%). Besides, chronic diseases also have significant association with sleep quality (Basnet et al., 2016). People with chronic diseases tend to have poorer sleep quality than healthy people at night (Basnet et al., 2016). Moreover, physical activity positively affects sleep quality (Evensen et al., 2017). Study done by Evensen et al., (2017) found that hospitalized patients have low level of physical activity and hospitalized ambulatory patients tend to spend only 1.1 hour per day in standing and walking in the hallways at the ward (Pedersen et al., 2013). This could be one of the reasons of the poor sleep quality among hospitalized patients.

\section{Mean difference between socio-demographic characteristics and sleep quality}

In this study, socio-demographic characteristics, which were selected for analysis, including age, gender, ethnicity, educational level, marital status, and experience of hospitalization were tested to identify their relationship with sleep quality. However, all these six socio-demographic characteristics had no significant mean difference with sleep quality.

\footnotetext{
Age

The finding of this study indicated that age and sleep quality had no significant mean difference where the $p$ value was 0.93 . Similar findings were also reported in Lei et al. (2009), Grandner et al. (2010) and Sekercioglu et al., (2015). Majority of the respondents were from the middle to old adult categories. Hence, it could not effectively analyse the mean difference between ages and sleep quality. Moreover, a study has
} 
supported this finding that young adults also experience poor sleep quality (Hung et al., 2013). Besides, the differences in the study population and the measurement tools might also contribute to the difference of results regarding the effects of age on sleep quality (Sekercioglu et al., 2015).

\section{Gender}

Although females had a higher PSQI mean score than males in this study, gender has no significant mean difference with sleep quality with $p$ value of 0.62 . This is in line with the findings of other studies (Meisinger $e t$ al., 2007; Shafi \& Shafi, 2017; Tang et al., 2017). Meisinger et al., (2007) explained that although women have longer sleeping time than men, there was no report of gender difference in sleep quality. Moradi et al. (2014) reported that a change in environment would affect one's sleep quality at night. Therefore, the environmental factors most probably affected sleep quality of both gender. External disturbances such as noise were more disruptive at night and hospitalized patients, regardless of gender would be affected (Lei et al., 2009).

\section{Educational level}

This study found that there was no significant mean difference between educational level and sleep quality ( $p$ value > 0.05). Lei et al. (2009) also found no significant mean different across educational level and sleep quality. Environmental factors are the main factors that would affect sleep quality of an individual (Moradi et al., 2014).However, a few studies had found contradictory result in which significant mean difference was indicated between educational level and sleep quality (Arber, Bote \& Meadows, 2009; Grandner et al., 2010). Arber, Bote and Meadows (2009) found that individual with lower educational level would have poorer sleep quality compared to those with higher educational level. People with higher education tend to have higher income which causes them to have less stress level and better sleep quality (Grandner et al., 2010). In contrast, a study reported that people with lower educational level have better sleep quality compared to those with higher education as they have lesser stress and relaxing lifestyle (Moradi et al., 2014). Therefore, the mean difference between educational level and sleep quality is still unknown.

\section{Marital status}

This study indicated that marital status has no significant mean difference with sleep quality ( $p$ value $=0.50)$. The researcher could not find any support regarding this finding. This is most probably due to the most of the respondents were married and thus, this study could not effectively analyse the mean difference between marital status and sleep quality. However, most of the previous studies indicated that people who are married tend to have better sleep quality at night (Grandner et al., 2010; Gu et al., 2010). They proposed that increasing positive support from the spouse would aid in better sleep quality (Stafford et al., 2017). Married people have greater marital harmony and less stress level compared to unmarried people and widow or widower (Grandner et al., 2010).

\section{Association between Each Chronic Diseases and Patients' Sleep Quality during Hospitalization Period}

In this study, all four chronic diseases (CVDs, HPT, Type II DM and CKD) had no significant association with sleep quality.

\section{CVDs and sleep quality}

No significant association was indicated between CVDs and sleep quality ( $p$ value $=0.43$ ). The researcher could not find support regarding the finding in this study. Yet, Basnet et al. (2016) reported that sleep quality of the individual most probably would not be affected by having only one single chronic disease. The sleep quality would mostly be affected if the individual is having more than one chronic disease (Basnet et al., 2016).

A contradicted finding was reported in Zalai \& Bohra (2016). They found CVDs has a significant association with sleep quality. People with CVDs tend to have poorer sleep quality than healthy people (Lao et al., 2018). Sleeping duration is one of the determinants of sleep quality (Meisinger et al., 2007). Having longer duration of sleep will increase the risk for CVDs (Chair et al., 2017). However, Lao et al. (2018) had reported that long sleep duration had no significant association with CVDs. While Nagai, Hoshide and Kario (2010) 
and Lao et al., (2018) reported that sustained short sleep duration could lead to adverse cardiovascular consequences.

\section{HPT and sleep quality}

In this study, HPT had no significant association with sleep quality ( $p$ value $=0.35$ ). Similar finding was indicated in Moradi et al., (2014) and Sekercioglu et al., (2015). However, Meisinger et al., (2007) reported a contradictory result whereby HPT was significantly associated to sleep quality in their study. The association might happen due to the biological mechanisms in the body where it would alter cortisol stress hormone and sympathetic nervous system (Shittu et al., 2014). The elevation of sympathetic activity caused the elevation of blood pressure (Meisinger et al., 2007). Other than that, poor sleep quality also contributed to the impaired handling of sodium, accelerated arterial stiffening and impaired cardiorenal hemodynamics which cause HPT (Thomopoulos et al., 2011).

\section{Type II DM and sleep quality}

There was no significant association between Type II DM and sleep quality in this study ( $p$ value $=0.96$ ). This is in line with Sekercioglu et al., (2015), where they reported that the presence of Type II DM was not an independent predictor for poor sleep quality. Different result was indicated in other studies (Mbatchou Ngahane et al., 2015; Li et al., 2016; Zalai \& Bohra, 2016). They found that Type II DM and sleep quality had a significant association. Poor sleep quality was associated with lower glucose tolerance and elevation of insulin resistance or reduced insulin sensitivity (Meisinger et al., 2007; Nagai, Hoshide \& Kario, 2010). Nagai, Hoshide \& Kario (2010) and Basnet et al. (2016) also reported that Type II DM was associated with poor sleep quality via endocrine system disruption, which would cause hormonal changes and affect eating behaviour and autonomic balance. Since poor sleep quality would disturb glucose-insulin metabolism and substrate-oxidation (Basnet et al., 2016), people with poor sleep quality has higher risk of developing Type II DM (Meisinger et al., 2007).

\section{CKD and sleep quality}

No significant association was also indicated between CKD and sleep quality ( $p$ value $=0.50$ ).
This is supported by Sekercioglu et al., (2015). Individuals with CKD always felt fatigue, therefore, they tend to have good sleep quality at night (Zalai $\&$ Bohra, 2016). Other than that, the difference of stages of CKD has different severity of disease process which contributed to difference in sleep quality (Zhang et al., 2014). The difference of assessment tools used might cause no significant association between CKD and sleep quality (Shafi \& Shafi, 2017). However, other earlier studies reported that CKD has a significant association with sleep quality. Basnet et al. (2016) indicated that poor sleep quality tended to increase the odds of CKD. One of the complications of CKD is anemia and it would cause alteration in sleep quality of patients with CKD (Zalai\& Bohra, 2016). Besides, patients with CKD have significantly lower nocturnal melatonin levels which lead to poor sleep quality at night (Maung et al., 2016). Moreover, poor sleep quality commonly found in individuals with co-morbid medical conditions (Maung et al., 2016).

\section{Association between Sleep Disorder and Sleep Quality}

In the present study, an agreement was found with the previous studies that a significant association was indicated between sleep disorder and sleep quality ( $p$ value $<0.001$ ) (El-Tantawy et al., 2014; Motlagh et al., 2017). A study reported that medications such as diuretics most probably related with a worsened sleep quality as it would cause urination and nocturia enuresis (Moradi et al, 2014). Urination and nocturia enuresis most probably would cause frequent night awakening which is one of the sleep disorder (Koyanagi et al., 2014).In addition, study also supported the potential role of sleep disorder in poor sleep quality (Moradi et al., 2014). Sleep disorders of daytime sleepiness and insomnia mostly happened among hospitalized patients when the change of environment, physical activity, social limitation and light exposure at night would have affected the melatonin secretion and worsened the sleep quality at night (Moradi et al., 2014).Sleep disorder would lead to redistribution of spending time in the different sleep stages (Halperin, 2014). Increasing stage 1 of sleep and decreasing slow wave sleep and REM sleep would cause shallower sleep and awake from 
sleep (Halperin, 2014). Sleep disorder also create additional stress to maximize sleep (Medic, Wille \& Hemels, 2017). This will in turn, contribute to worsened sleep quality (Medic, Wille \& Hemels, 2017).

\section{CONCLUSION}

The findings of this study showed that among the hospitalized patients with chronic diseases, more than half of the respondents of this study $(59.0 \%)$ selfclaimed that they have sleep disorder. Based on thAmericane PSQI, majority of the respondents $(74.4 \%)$ had poor sleep quality during their hospitalization in Hospital USM. However, no significant association was found between sociodemographic characteristics and their sleep quality. This also applied to each chronic disease (CVDs, HPT, Type II DM and CKD) and their sleep quality. On the other hand, a significant association was found between sleep disorders and sleep quality. This study provides insights into the prevalence of sleep disorder, sleep quality level, association between socio-demographic characteristics, chronic diseases on sleep quality and sleep disorder on sleep quality. It is important for health care providers to treat effectively the medical conditions to optimize sleep continuity of patients. Besides, the poor sleep quality level of hospitalized patients with chronic diseases most probably resulted due to external factors such as the environment. These findings indicate no association between each chronic disease and socio-demographic characteristics with sleep quality, but prospective studies are needed to understand the complex interaction between them.

\section{ACKNOWLEDGEMENT}

We would like to acknowledge all the patients who were involved as the respondents of this study.

\section{REFERSENCE}

American Psychiatric Association. (2017). What are Sleep Disorders. Retrieved from: https://www.psychi atry.org/patients-families/sleep-disorders/what-aresleep-disorders.

American Sleep Association. (2017). Sleep and Sleep Disorder Statistics.Retrieved from: https://www.sleepassociationhttps://www.sleepassociation.org/slee p/sleep-statistics/.

American Sleep Association. (2017). What is Sleep? Why is it needed. Retrieved from: https://www.slee pas-sociation.org/patients-general-public/what-issleep/.

Anderson, C. (2010). The Impact of Sleep on Dealing with Daily Stressors-A Need for Controlled Laboratory Evidence. Stress and Health, 26(3), pp 194-197. doi:10.1002/smi.1301.

Arber, S., Bote, M. \& Meadows, R. (2009). Gender and Socio-economic Patterning of Self-reported Sleep Problems in Britain. Social Science \& Medicine, 68(2), pp 281-289.

Auckley, D., Benca, R. \& Eichler, A. F. (2018). Poor Sleep in the Hospital: Contributing Factors and Interventions. Retrieved from :https://www. uptodate.com/contents/poor-sleep-in-the-hospitalcontributing-factors-and-interventions\#H3079 236310 .

Azri, M. A., Dahlan, A., Masuri, M. G. \& Isa, K. A. M. (2016). Sleep Quality among Older Persons in Institutions. Procedia - Social and Behavioral Sciences, 234, pp 74-82.

Barbosa, K. T. F., Oliveira, F. M. R. L., Oliveira, S. M., Gomes, M. O. \& Fernandes, M. G. M. (2016). Sleep Quality in Elderly Patients in Outpatient Care. Journal Of Nursing, 10(2), pp 756-761.

Basnet, S., Merikantoa, I., Lahtia, T., Männistö, S., Laatikainena, T., Vartiainen, E. \& Partonen, T. (2016). Associations of Common Chronic Noncommunicable Diseases and Medical Conditions with Sleep-related Problems in a Population-based Health Examination Study. Sleep Science, 9(3), pp 249-254.

Chair, S. Y., Wang, Q., Cheng, H. Y., Lo, S. W., Li, X. M.,Wong, E. M. \& Sit, J. W.(2017). Relationship between sleep quality and cardiovascular disease risk in Chinese post-menopausal women. BMC Women's Health, 17(79), pages 7.

Chan, A. L.(2016). Problems Staying Asleep: Why You're Waking Up in the Middle of the Night. 
Retrieved from: https://www.huffingtonpost. in/entry/wake-up-in-the-middle-of-the-nightmiddle-insomnia_n_3353541

Clares, J. W. B., Freitas, M. C., Galiza, F. T. \& Almeida, P. C. (2012). Sleep and Rest Needs of Seniors: A Study Grounded in the Work of Henderson. Acta Paul Enferm, 25(Special Issue 1), 54-59.

Cornu, J. N., Abrams, P., Chapple, C. R., Dmochowski, R. R., Lemack, G. E., Michel, M. C., Tubaro, A., \& Madersbacher, S. (2012). A Contemporary Assessment of Nocturia: Definition, Epidemiology, Pathophysiology, and Management-A Systematic Review and Meta-analysis. European Urology, 62(5), pp 877-890.

Costa, S. V. \& Ceolim, M. F. (2013). Factors that affect inpatients' quality of sleep. Revista Escola Enfermagem da USP, 47(1), pp 46-52.

El-Tantawy, A. M. A., Al-Yahyac, A. H., Raya, Y. M. \& Mohamed, S. A. (2014). Sleep Disorders and Sleep Quality among Patients with Anxiety or Depressive Disorders in Relation to Their Quality of Life. Egyptian Journal of Psychiatry, 35(1), pp 56-64. doi: 10.4103/1110-1105.127284.doi:10.4103/11101105.127284 .

Evensen, S., Sletvold, O., Lydersen, S. \& Taraldsen, K. (2017). Physical activity among hospitalized older adults - an observational study. BMC Geriatrics, 17(110), p 8. Doi: 10.1186/s12877-017-0499-z.

Gangwisch, J. E., Heymsfield, S. B., Boden-Albala, B., Buijs, R. M., Kreier, F., Opler, M. G., Pickering, T.G., Rundle, A.G., Zammit, G.K. \& Malaspina, D. (2008). Sleep Duration Associated with Mortality in Elderly, but not Middle-Aged, Adults in a Large US Sample. Sleep, 31(8), pp 1087-1096.

Gezer, I. A., Balkarli, A., Can, B., Bağçaci, S., Küçükşen, S. \& Küçük, A. (2017). Pain, Depression Levels, Fatigue, Sleep Quality, and Quality of Life in Elderly Patients with Rheumatoid Arthritis. Turkish Journal of Medical Sciences. 47, pp 847853. doi:10.3906/sag-1603-147.

Grandner, M. A., Patel, N. P., Gehrman, P. R., Xie, D. W., Sha, D., Weaver, T. \& Gooneratne, N. (2010). Who Gets the Best Sleep? Ethnic and
Socioeconomic Factors Related to Sleep Complaints. Sleep Medicine, 11(5), pp 470-478. doi:10.1016/j.sleep.2009.10.006.

Gu, D., Sautter, J., Robin Pipkin, R. \& Zeng, Y. (2010). Sociodemographic and Health Correlates of Sleep Quality and Duration among Very Old Chinese. Sleep, 33(5), pp 601-610.

Hacker, E. D., Kapella, M. C., Park, C., Ferrans, C. E. \& Larson, J. L. (2015). Sleep Patterns During Hospitalization Following Hematopoietic Stem Cell Transplantation. Oncology Nursing Forum, 42(4), pp 371-379. doi:10.1188/15.QNF.371-379.

Haile, Y. G., Alemu, S. M. \& Habtewold, T. D. (2017). Insomnia and Its Temporal Association with Academic Performance among University Students: A Cross-Sectional Study. Bio Med Research International, pages 7. doi: 10.1155/2017/2542367.

Halperin, D. (2014). Environmental Noise and Sleep Disturbances: A Threat to Health? Sleep Science, 7(4), pp 209-212.

Healthy Sleep. (2007). External Factors that Influence Sleep. Retrieved from: http:/healthysleep.med.harvard .edu/healthy/science/how/external-factors.

Hein, M., Lanquart, J. P., Loas, G., Hubain, P. \& Linkowski, P. (2017). Prevalence and Risk Factors of Moderate to Severe Obstructive Sleep Apnea Syndrome in Insomnia Sufferers: A Study on 1311 Subjects. Respiratory Research, 18(135), pages 10. Doi: 10.1186/s12931-017-0616-8.

Holland, J. C., Breitbart, W. S., Jacobson, P. B., Lederbarg, M. S., Loscalzo, M. J.\& Mccorkle, R. S.(2010).Psycho-Oncology, 2nd Edition, Oxford University Press, UK

Hung, H. C., Yang, Y. C., Ou, H. Y., Wu, J. S., Lu, F. H., \& Chang, C. J. (2013). The Association Between Self-reported Sleep Quality and Metabolic Syndrome. PloS one. 8(1), pages 6.

Institute for Public Health (IPH). (2015). National Health and Morbidity Survey 2015 (NHMS 2015).Vol. II: Non-Communicable Diseases, Risk Factors \& Other Health Problems. Retrieved from: file:///C:/Users/ LUC-KOL//Desktop/nhmsreport 2015vol2.pdf 
Isaia, G., Corsinovi, L., Bo, M., Santos-Pereira, P. S., Michelis, G., Aimonino, N. \& Zanocchi, M. (2011). Insomnia among Hospitalized Elderly Patients: Prevalence, Clinical Characteristics and Risk Factors. Archives of Gerontology and Geriatrics, 52(2), pp 133-137. doi:10.1016/j.archger.2010.03.001.

Ismail, T. N. N. T., Kassim, N. K., Abdullah, B. \& Adnan, M. M. (2017). Prevalence and Factors Associated with Obstructive Sleep Apnea among Patients with Chronic Illnesses in Hospital Universiti Sains Malaysia. International Medical Journal, 24(1), PP 114-116.

Kim, K. W., Yoon, I. Y., Chung, S., Shin, Y. K., Lee, S. B., Choi, E. A., Park, J. H. \& Kim, J. M. (2010). Prevalence, Comorbidities and Risk Factors of Restless Legs Syndrome in the Korean Elderly Population - Results from the Korean Longitudinal Study on Health and Aging. Journal of Sleep Research, 19, pp 87-92. doi: 10.1111/j.13652869.2009.00739.x.

Kishi, A., Natelson, B. H., Togo, F., Struzik, Z. R., Rapoport, D. M. \& Yamamoto, Y. (2011). SleepStage Dynamics in Patients with Chronic Fatigue Syndrome with or Without Fibromyalgia. Sleep, 34(11),pp 1551-1560. doi: 10.5665/sleep.1396.

Koyanagi, A., Garin, N., Olaya, B., Ayuso-Mateos, J. L., Chatterji, S., Leonardi, M., Koskinen, S., Tobiasz-Adamczyk, B. \& Haro, J. M. (2014) Chronic Conditions and Sleep Problems among Adults Aged 50 years or over in Nine Countries: A Multi-Country Study. PLOS ONE, 9(12), pages 17. doi: 10.1371/journal.pone.0114742.

Kripke, D. F., Langer, R. D., Elliott, J. A., Klauber, M. R. \& Rex, K. M. (2011). Mortality Related to Actigraphic Long and Short Sleep. Sleep Medicine, 12(1), pp 28-33. doi: 10.1016/j.sleep.2010.04.016.

Krueger, P. M. \& Friedman, E. M. (2009). Sleep Duration in the United States: A Cross-sectional Population-based Study. American Journal of Epidemiology, 169(9), pp 1052-1063. doi: 10.1093/aje/kwp023.

Lai, P. P. \& Say, Y. H. (2013). Associated Factors of Sleep Quality and Behavior among Students of
Two Tertiary Institutions in Northern Malaysia. Medical Journal of Malaysia, 68(3), pp 196203.

Lao, X. Q., Liu, X., Deng, H. B., Chan, T. C., Ho, K. F., Wang, F., Vermeulen, R., Tam, T., Wong, M. C. S., Tse, L. A., Chang, L. Y. \& Yeoh, E. K. (2018). Sleep Quality, Sleep Duration, and the Risk of Coronary Heart Disease: A Prospective Cohort Study With 60,586 Adults. Journal of Clinical Sleep Medicine, 14(1), pp 109-117. doi: 10.5664/jcsm.6894.

Lei Z, Qiongjing, Y., Qiuli, W., Sabrina, K., Xiaojing, L. \& Changli, W. (2009). Sleep quality and sleep disturbing factors of inpatients in a Chinese general hospital. Journal of Clinical Nursing, 18(17), pp 2521-2529. doi: 10.1111/j.1365-2702.2009.02846.x.

Li, Y., Gao, X., Winkelman, J. W., Cespedes, E. M., Jackson, C. L., Walters, A. S., Schernhammer, E., Redline, S. \& Hu, F. B. (2016). Association Between Sleeping Difficulty and Type 2 Diabetes in Women. Diabetologia, 59(4), pp 719-727. doi:10.1007/s00125015-3860-9.

Liam, C. K., Pang, Y. K., Shyamala, P. \& Chua, K. T. (2007). Obstructed Breathing During Sleep and Obstructive Sleep Apnoea Syndrome- Assessment and Treatment. Medical Journal of Malaysia, 62(3), pp 268-274.

Maung, S. C., Sara, A. E., Chapman, C., Cohen, D. \& Cukor, D. (2016). Sleep Disorders and Chronic Kidney Disease. World Journal of Nephrology, 5(3), pp 224-232. DOI:10.5527/wjn.v5.i3.224.

Mbatchou Ngahane, B. H., Nganda, M. M., Dzudie, A., Luma, H., Kamdem, F., Ngote, H. R., Monkam, Y., Kuaban, C. (2015). Prevalence and Determinants of Excessive Daytime Sleepiness in Hypertensive Patients: A Cross-sectional Study in Douala, Cameroon. BMJ Open, 5(7), pages 5. doi: 10.1136/bmjopen-2015-008339.

Medic, G., Wille, M. \& Hemels, M. E. (2017). Shortand Long-term Health Consequences of Sleep Disruption. Nature and Science of Sleep, 9, pp 151-161.

Meisinger, C., Heier, M., Löwel, H., Schneider, A. \& 
Döring, A. (2007). Sleep Duration and Sleep Complaints and Risk of Myocardial Infarction in Middle-aged Men and Women from the General Population: the MONICA/KORAAugsburg Cohort Study. SLEEP, 30(9), pp 1121-1127.

Moradi, M., Mehrdad, N., Nikpour, S., Haghani, H., Aalaa, M., Sanjari, M. \& Sharifi, F. (2014). Sleep Quality and Associated Factors among Patients with Chronic Heart Failure in Iran. Medical Journal of the Islamic Republic of Iran, 28(149), pages 7.

Motlagh, S. J., Shabany, M., Haghighi, K. S., Nasrabadi, A. N. \& Razavi, S. H. E. (2017). Relationship Between Sleep Quality, Obstructive Sleep Apnea and Sleepiness During Day With Related Factors in Professional Drivers. Acta Medica Iranica, 55(11), pp 691-695.

Nagai, M., Hoshide, S. \& Kario, K. (2010). Sleep Duration as a Risk Factor for Cardiovascular Disease- a Review of the Recent Literature. Current Cardiology Reviews, 6(1), pp 54-61.

National Sleep Foundation. (2017). Melatonin and Sleep.Retrieved from: https://sleepfoundation.org /sleep-topics/melatonin-and-sleep.

National Sleep Foundation. (2017). SleeptionaryDefinitions of Common Sleep Terms. Retrieved from: https://sleepfoundation.org/sleeptionary

National Sleep Foundation. (2017). Snoring and Sleep. Retrieved from: https://sleepfoundation.org/sleepdisorders-problems/other-sleep-disorders/snoring

National Sleep Foundation. (2017). What Happens When You Sleep? Retrieved from: https://sleepfoundation.org/how-sleep-works/what-happens-when-you-sleep.

Palacios Ceña, M., Fernandez-Munoz, J. J., Castaldo, M., Wang, K., Guerrero-Peral, A., Arendt-Nielsen, L. \& Fernandez-de-Las-Penas, C. (2017). The association of headache frequency with pain interference and the burden of disease is mediated by depression and sleep quality, but not anxiety, in chronic tension type headache. The Journal Headache and Pain, 18(19), pages 8 . doi: 10.1186/s10194-017-0730-5.

Park, J. E., Bae, S. H., Choi, Y. J., Choi, W. C., Kim, H. W. \& Lee, U. L. (2017). The Structural Changes of
Pharyngeal Airway Contributing to Snoring after Orthognathic Surgery in Skeletal Class III Patients. Maxillofacial Plastic and Reconstructive Surgery. 39 (22). pages 9. Doi: 10.1186/s40902-017-0120-6.

Pedersen, M. M., Bodilsen, A. C., Petersen, J., Beyer, N., Andersen, O., Lawson-Smith, L., Kehlet, H. \& Bandholm, T. (2013). Twenty-Four-Hour Mobility during Acute Hospitalization in Older Medical Patients. The Journals of Gerontology. 68(3), pp 331-337. doi:10.1093/gerona/gls165.

Prince, D., Pedler, K. \& Rashid, P. (2012). Nocturia - A Guide to Assessment and Management. Australian Family Physician, 41(6), pp 399-402.

Punjabi, N. M. (2008). The Epidemiology of Adult Obstructive Sleep Apnea. American Thoracic Society, 5(2), pp 136-143. doi: 10.1513/pats.200709-155MG.

Sekercioglu, N., Curtis, B., Murphy, S. \& Barrett, B. (2015). Sleep Quality and Its Correlates in Patients with Chronic Kidney Disease: A Cross-sectional Design. Renal Failure, 37(5), pp 757-762. doi: 10.3109/0886022X.2015.1024555.

Shafi, S. T. \& Shafi, T. (2017). A Comparison of Quality of Sleep Between Patients with Chronic Kidney Disease not on Hemodialysis and End-stage Renal Disease on Hemodialysis in a Developing Country. Renal Failure, 39(1), pp 623-628. doi:10.1080/0886022X.2017.1361836.

Sharma, S., Chowdhury, A., Tang, L., Willes, L., Glynn, B. \& Quan, S. F. (2016). Hospitalized Patients at High Risk for Obstructive Sleep Apnea Have More Rapid Response System Events and Intervention is Associated with Reduced Events. PLoS ONE, 11(5), pages 9. doi:10.1371/journal.pone.0153790.

Shittu, R. O., Issa, B. A., Olanrewaju, G. T., Odeigah, L. O., Sule, A. G., Sanni, M. A, Aderibigbe, S. A., Uthman, M. B. \& Nyamngee, A. A. (2014). Association between Subjective Sleep Quality, Hypertension, Depression and Body Mass Index in a Nigerian Family Practice Setting. Journal of Sleep Disorders \& Therapy, 3(2), pages 5. doi:10.4172/2167-0277.1000157.

Smaldone, A., Honig, J. C., \& Byrne, M. W. (2007). 
Sleepless in America: Inadequate Sleep and Relationships to Health and Well-being of Our Nation's Children. Pediatrics, 119( Supple1), s29s37. doi:10.1542/peds.2006-2089F.

Smith, M., Robinson, L. \& Segal, R. (2017). Sleep Needs: What to Do If You're Not Getting Enough Sleep. Retrieved from:https://www .helpguide.org/articles/sleep/sleep-needs-get-thesleep-you-need.htm?pdf=true

Stafford, M., Bendayan, R., Tymoszuk, U. \& Kuh, D. (2017). Social support from the closest person and sleep quality in later life: Evidence from a British birth cohort study. Journal of Psychosomatic Research, 98, pp 1-9. 10.1016/j.jpsychores.2017.04.014.

Tang, J., Liao, Y. H., Kelly, B. C., Xie, L., Xiang, Y. T., Qi, C., Pan, C., Hao, W., Liu, T. Q., Zhang, F. Y. \& Chen, X. G. (2017). Gender and Regional Differences in Sleep Quality and Insomnia: A General Population-based Study in Hunan Province of China. Scientific Reports. Pages 9. doi: 10.1038/srep43690.

Thomopoulos, C., Michalopoulou, H., Kasiakogias, A., Kefala, A. \& Makris, T. (2011). Resistant Hypertension and Obstructive Sleep Apnea: The Sparring Partners. International Journal of Hypertension, pages 5. doi:10.4061/2011/947246.

Tikkinen, K. A. O., Johnson, T. M., Tammela, T. L. J., Sintonen, H., Haukka, J., Huhtala, H. \& Auvinen, A. (2010). Nocturia Frequency, Bother, and Quality of Life: How Often is Too Often? A Population-Based Study in Finland. European Urology.57(3), pp
488-496. doi:10.1016/j.eururo.2009.03.080.

Ünsal, A. \& Demir, G. (2012). Evaluatıon of Sleep Quality and Fatigue in Hospitalized Patients. International Journal of Caring Sciences, 5(3), pp 311-319.

Wali, S. O., Abalkhail, B. \& Krayem, A. (2017). Prevalence and Risk Factors of Obstructive Sleep Apnea Syndrome in a Saudi Arabian Population. Annals of Thoracic Medicine, 12(2), pp 88-94.

Wang, Y., Hu, H., Xu, K., Zhang, X., Wang, X., Na, Y. \& Kang, X. (2015). Prevalence, Risk Factors, and Symptom Bother of Nocturia: A Population Based Survey in China. World Journal of Urology, 33(5), pp 677-683. doi: 10.1007/s00345-014-1411-5.

World Health Organization. (2017). Noncommunicable diseases. Retrieved from: http://www.who.int/m ediacentre/factsheets/fs355/en/

Zailinawati, A. H., Mazza, D. \& Cheong, L. T. (2012). Prevalence of insomnia and its impact on daily function amongst Malaysian primary care patients. Asia Pacific Family Medicine, 11(9), pages 8.

Zalai, D. \& Bohra, M. (2016). Fatigue in Chronic Kidney Disease: Definition, Assessment and Treatment. CANNT Journal, 26(1), pp 39-44.

Zhang, J., Wang, C., Gong, W., Peng, H., Tang, Y., Li, C. C., Zhao, W., Ye, Z. \& Lou, T. (2014). Association Between Sleep Quality and Cardiovascular Damage in Pre-dialysis Patients with Chronic Kidney Disease. BMCNephrology, 15(131), pages 9. 